\title{
Prompt simulation of the transfer of radioactivity in the Irish food chain following a nuclear accident
}

\author{
P. McGinnity, K.J. Smith, C.A. McMahon and P.A. Colgan \\ Radiological Protection Institute of Ireland, 3 Clonskeagh Square, Dublin 14, Ireland
}

\begin{abstract}
The ARGOS Food and Dose Module has been adopted by the RPII to simulate the transfer of radioactivity in the food chain in the event of a large scale nuclear incident and to enhance its capability to assess the radiological consequences. This paper describes adaptation of this model for Irish conditions and its intended use, illustrated with examples from a recent national emergency exercise. By enabling time series of activity concentrations of individual radionuclide or radionuclide groups in a range of food and animal feeds and comparison with appropriate action levels, the model would assist the formulation of early advice regarding countermeasures and would be an important factor in refining a pre-defined sampling strategy. The current implementation provides a basis for more detailed modelling which would inevitably be required in the event of a real incident. As the situation evolved and monitoring results became available, FDM could be refined and used to predict future concentrations or those over a wide spatial area with increased confidence.
\end{abstract}

\section{INTRODUCTION}

Due to Ireland's distance from overseas nuclear facilities, ingestion of food containing elevated levels of radionuclides is considered to be the most significant potential exposure pathway to the population in the event of a large scale nuclear incident with the potential to contaminate a wide area of the country. This exposure could be almost entirely prevented by the introduction of appropriate controls on the distribution and consumption of food. Careful and timely management of emergency response, based on analysis of the known situation and on prognosis, would be vital in order to mitigate the contamination of agricultural land, disruption to agricultural practices and potentially long-term economic effects. The agri-food industry is an important sector of the Irish economy, accounting for $8.1 \%$ of gross domestic product according to the Department of Agriculture and Food [1].

The RPII has responsibility under the National Emergency Plan for Nuclear Accidents (NEPNA) to assess potential contamination of the food chain and to advise on related countermeasures. The adoption of the ARGOS Food and Dose Module (FDM), with which the transfer of radioactivity in the Irish food chain can be simulated, has enhanced the RPII's capability in this area. This paper describes the customisation of input data sets necessary to generate valid results for Irish conditions. Its intended use in the event of such an incident is also described, illustrated with examples from a recent national emergency exercise which focussed on the management of radioactively contaminated agricultural land and food production systems.

\section{DESCRIPTION OF THE MODEL}

FDM is based on the ECOSYS-87 radiological simulation model which is well-documented [2] and established in European nuclear emergency management systems such as RODOS [3] and ARGOS [4]. The most important compartments and transfer processes are considered to simulate the time-dependent radionuclide contamination of food after accidental deposition onto agricultural land. These include:

- dry and wet deposition to and interception by soil and plants;

- foliar uptake, weathering effects (rain, wind), radioactive decay and growth dilution; 
- root uptake, fixation, desorption and leaching;

- resuspension of contaminated soil;

- translocation;

- transfer from animal feed to animal products;

- dilution and concentration resulting from processing of food and animal feed; and

- storage factors.

The subsequent radiation exposure of people via all relevant exposure pathways may also be calculated.

\subsection{Data describing Irish agricultural, climatic and other conditions}

FDM is supplied with default input datasets which describe agricultural, climatic and other conditions for Central European regions. These parameters are described in Müller and Pröhl [2] and Pröhl [5]. Some of this default data, mainly element and radionuclide specific data such as environmental transfer factors and physical and biological half lives, are applicable for all regions of interest. However some parameters are highly sensitive to the characteristics of the region where deposition takes place.

The RPII has therefore customised a number of the default parameter datasets to adapt the models for Irish conditions. This was achieved through consultation with a number of organisations: the Department of Agriculture, Fisheries and Food (DAFF), Teagasc (the Irish Agriculture and Food Development Authority), the Food Safety Authority of Ireland (FSAI) and the Central Statistic Office (CSO). Firstly the most significant crops, livestock and processed products used as food and animal feed and which are produced in Ireland were defined. Modified parameters then included:

- growing season, yields and maximum leaf area index for grass;

- dates for preparation of hay and silage;

- sowing and harvest dates for field and horticultural crops;

- variation of foliar coverage for field and horticultural crops;

- types and volume of feed fed to livestock at various periods during the year;

- average age of animals at slaughter;

- human food consumption rates (for calculation of ingestion dose) [6];

- agricultural production statistics (for calculation of collective dose) [7]; and

- human demographics (for calculation of collective dose) [8].

Other parameters from the default datasets were verified for consistency with the modified data. These included:

- deposition velocities for the crop types considered;

- growth dilution rates for pasture;

- element specific factors including soil-plant transfer factors; retention coefficients and translocation factors for the crop types considered;

- element specific factors including feed-animal transfer factors and biological half lives and metabolism factors for the livestock types considered;

- processing and storage factors for the foods and animal feeds considered;

As a first approximation Ireland is treated as a single ecoregion based on the assumption that there are only minor regional differences in climate, farming practices or other relevant characteristics. Differences in soil-plant transfer due to variations in soil properties have also been neglected as a first approximation. In the early stages of an emergency, foliar deposition is the key consideration.

\subsection{Data describing a specific deposition event}

Parameters describing a specific radiological deposition event are also required. By default the following input is used:

- the time-integrated activity concentration (TIAC) in near-ground air of each radionuclide of interest;

- wet deposition levels of each radionuclide of interest; 
- precipitation intensity; and

- date and time of the deposition event.

This is derived from atmospheric dispersion models. The input parameters are averaged over multiple, user-defined spatial areas which are used as the basis for calculations in FDM. Two independent sets of calculation areas have been defined covering the whole country with coarse (26 units) and fine (4,334 units) resolution. The former, based on county definitions, is generally sufficient for most, large scale emergency response applications and in exercises.

\section{RESULTS}

The steps involved in a typical FDM simulation are described in this section. The RPII operates the Rimpuff atmospheric dispersion model [9] and FDM using the ARGOS nuclear decision support system which since 2001 it has used as its primary tool for technical assessment of a nuclear or radiological incident. As illustration, examples derived from a hypothetical release from the Wylfa Nuclear Power Plant in the UK (the closest nuclear facility to Ireland) are presented. This scenario formed the basis of a recent national emergency exercise which focussed on the mitigation and remediation phases of a nuclear incident in Ireland.

- Rimpuff, driven by HIRLAM Numerical Weather Prediction data supplied by Met Éireann (Irish National Weather Service), is used to calculate activity concentrations in near-ground air in hourly time steps. In Figure 1 the instantaneous concentration of I-131 in air is displayed for the example scenario. Radar rainfall, from which rainfall intensity values are derived and used in Rimpuff's wet deposition calculation, is also displayed.

- Time-integrated activity concentration, deposition and dose rates are calculated by Rimpuff. In Figure 2 the TIAC of I-131, integrated over the period of plume passage, is displayed. Counties (coarse FDM calculation areas) are overlaid.

- The required FDM input parameters (radionuclide-specific TIAC and wet deposition levels; and rainfall intensity) are derived by averaging over each county. Activity concentrations of individual radionuclides or groups of radionuclides in a range of foods and animal feeds are then calculated by FDM. In Figure 3 peak I-131 activity concentrations in milk in each county unit are presented.

- Predicted activity concentrations are normally compared with European Union (EU) Maximum Permitted Levels (MPL) of radioactive contamination of foodstuffs and feedingstuffs [10]. In Figure 4, the predicted variation with time of the activity concentration of I-131 in milk for selected counties is displayed and compared to the MPLs for Baby Foods and Dairy Produce.

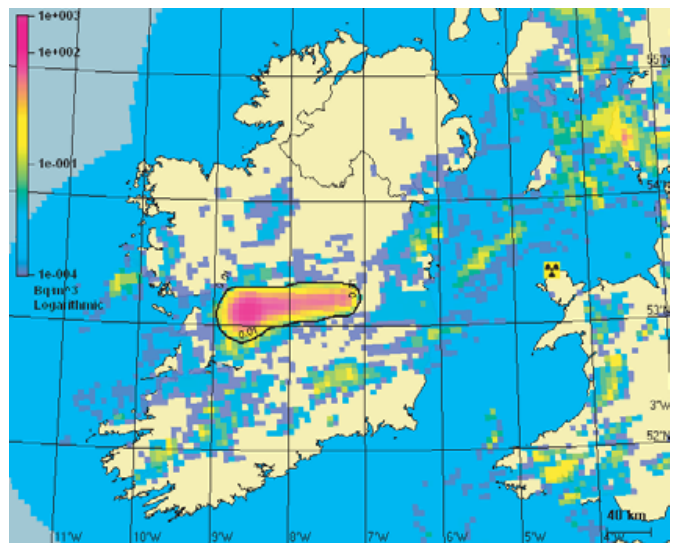

Figure 1. Instantaneous concentration of I-131 in air for the example scenario. Radar rainfall, from which rainfall intensity values are derived and used in Rimpuff's wet deposition calculation, is also displayed. 


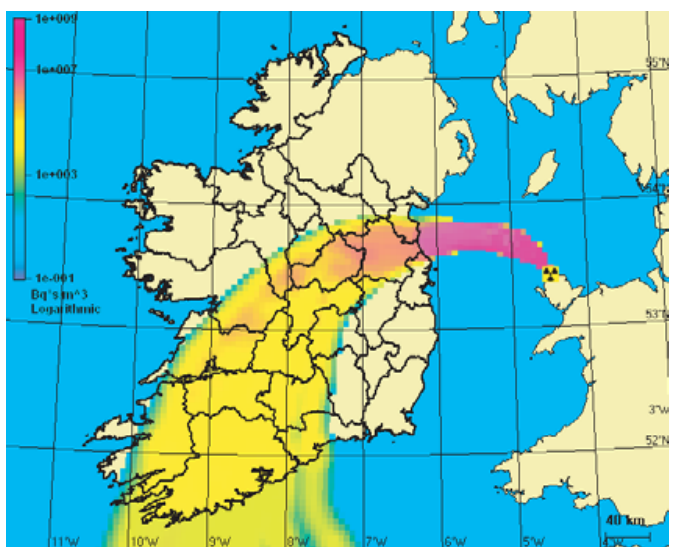

Figure 2. Time-integrated activity concentration of I-131, integrated over the period of plume passage, for the example scenario. Counties (FDM calculation areas) are overlaid.

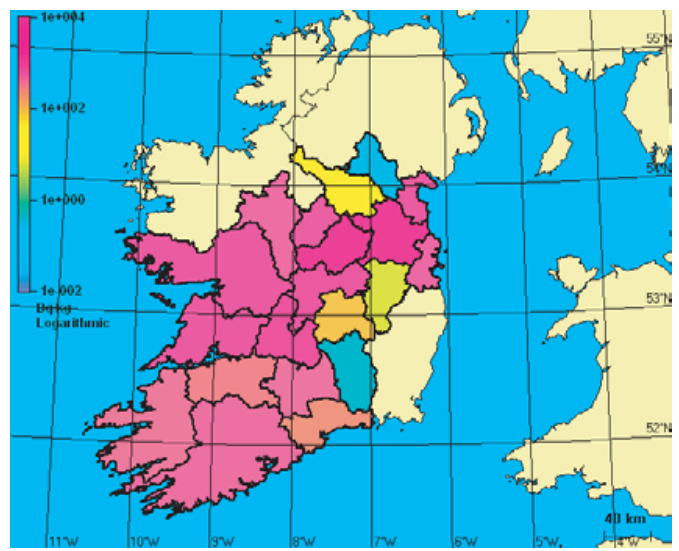

Figure 3. Peak I-131 activity concentrations in milk in each county for the example scenario.

1-131 in Milk

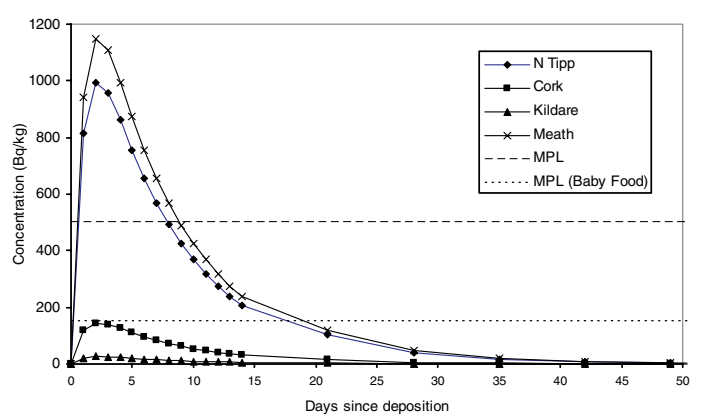

Figure 4. Predicted variation with time of the activity concentration of I-131 in milk for selected counties for the example scenario. Appropriate EU MPLs are also displayed.

FDM can also be operated in 'screening' mode in ARGOS. In this mode, a table is generated displaying the dates between which predicted activity concentrations in each food type and county exceed defined action levels. 


\section{CONCLUSIONS}

The adaptation of ARGOS FDM for Irish conditions and its intended use have been described. In the event of significant deposition of radionuclides following a nuclear incident, FDM results would be compared with predefined action levels (EU MPLs) and used by the RPII and other organisations with nuclear or radiological emergency responsibilities to formulate early advice regarding countermeasures. Recently the model was used successfully during a national emergency exercise and helped to facilitate meaningful discussion between participants from a variety of disciplines.

FDM offers prompt food chain modelling capability, which has been adapted for Irish conditions but based on the established and verified transfer processes which comprise the model (for example [11]). FDM results would be an important factor in the prioritisation and targeting of environmental and food sampling resources. As monitoring results became available, FDM input parameters could be refined and used to predict future concentrations or concentrations over a wide spatial area with increased confidence. It would also be possible to use radionuclide-specific, wide-area survey monitoring data as input instead of dispersion modelling results, thus increasing the accuracy of calculations. The current implementation provides a basis for more detailed modelling (e.g. with higher spatial resolution or to consider different production systems within a specific food product) which would inevitably be required (and justified) in the event of a real incident.

Currently it is assumed in FDM that no countermeasures are implemented in the contaminated area. However, an extension of the model which will enable calculations of the effect of countermeasures on the transfer of radioactivity is currently in preparation. This will enable various countermeasure strategies to be evaluated.

\section{Acknowledgments}

The cooperation of Teagasc, DAFF, FSAI, CSO in supplying data and advice is gratefully acknowledged. Invaluable assistance was provided by the ARGOS developers at the Prolog Development Center and Steen Hoe at the Danish Emergency Management Agency.

\section{References}

[1] Department of Agriculture and Food, Annual Review and Outlook for Agriculture and Food 2006/2007, Retrieved 11 March 2008 from http://www.agriculture.ie/publicat/publications2007/ ARO/ARO_English.pdf.

[2] Müller H. and Pröhl G., Health Physics, 64 (1993) 232-252.

[3] Ehrhardt J., Brown J., French S., Kelly G.N., Mikkelsen T., Müller H., Kerntechnik, 62 (1997) $122-128$.

[4] Hoe S., Müller H. and Thykier Nielsen, S., in Proceedings of the $10^{\text {th }}$ International Congress of the International Radiation Protection Association, Hiroshima, 2000. P-11-288.

[5] Pröhl G., Modellierung der Radionuklidausbreitung in Nahrungsketten nach Deposition von Sr-90, Cs-137 und I-131 auf landwirtschaftlich genutzte Flächen 1990. Gesellschaft für Strahlen- und Umweltforschung (GSF), Neuherberg, GSF-Bericht 29/90.

[6] Irish Universities Nutrition Alliance, North/South Ireland Food Consumption Survey, Summary Report, 2001. Retrieved 6 March 2008 from http://www.iuna.net/survey2000.htm.

[7] Central Statistics Office, Census of Agriculture Main Results, 2000. Retrieved 6 March 2008 from http://www.cso.ie/releasespublications/pr_agrifishpubshardcopies.htm.

[8] Central Statistics Office, Population and area of each Province, County, City, urban area, rural area and Electoral Division, 2002 and 2006, 2007. Retrieved 11 March 2008 from http://beyond2020.cso.ie/Census/TableViewer/tableView.aspx?ReportId=1765. 
[9] Thykier-Nielsen, S., Deme, S., Mikkelsen, T., Description of the Atmospheric Dispersion Module RIMPUFF, 1998. RODOS(WG2)-TN(98)-02.

[10] Council of the European Community Council, Council Regulation (EEC) No 2219/89, Off. J. Eur. Commun., L221 (1989) 4-5.

[11] Hinton T.G., Health Physics, 66 (1994) 513-31. 